Coastal Engineering Journal, Vol. 57, No. 1 (2015) 1502001 (5 pages)

(c) World Scientific Publishing Company and Japan Society of Civil Engineers DOI: $10.1142 / \mathrm{S} 0578563415020015$

\title{
Editorial
}

\section{XtremRisK - Today's and Future Coastal Flood Risks Under Extreme Events}

\author{
Andreas Kortenhaus* and Hocine Oumeraci ${ }^{\dagger}$ \\ *Department of Civil Engineering, Ghent University, \\ Technologiepark 904, 9052 Zwijnaarde (Ghent), Belgium \\ ${ }^{\dagger}$ Leichtweiß-Institute for Hydraulic Engineering and Water Resources, \\ Technische Universität Braunschweig, \\ Beethovenstr. 51a, 38106 Braunschweig, Germany
}

Accepted 26 February 2015

Published 26 March 2015

\begin{abstract}
About Flood Risk
Climate change and sea level rise, storm surges and hurricanes, sustainability and preparedness are keywords when dealing with safety issues and flood protection along the world's coasts and estuaries. Scientific investigations and political discussions of the related questions are manifold and have looked into various aspects of coastal flood risk. However, the definition of "risk" alone has kept scientists busy all over the world and whilst disputes about its meaning can be found in literature, an easy-to-apply generic definition is yet simply not available.

The term "risk" has been developed involving a wide range of disciplines all of which seem to have different viewpoints and definitions of risk. It is therefore inevitable to define its meaning before commencing any risk assessment or risk management attempts. The papers in this issue deal with various aspects of coastal flood risk in general and most of them use an engineering approach to risk which is defined here as the probability of a flood times its consequences. Whilst this seems a straightforward definition it implies numerous questions which have not been answered and some of which have not even been addressed yet. What con-
\end{abstract}


sequences are we talking about? Human lives? Cultural? Economic? And how can these consequences be assessed and used for risk analyses? What are their units? With the ambiguity in the definition of risk and the open questions which consequences to include the assessment of risk is extremely difficult and the outcomes of different studies remain almost impossible to compare.

Flood risk is changing over time due to many different influences. Climate change is one of these factors and is believed to result in warmer and wetter winters and hotter and drier summers, hence more extreme events. But is there a physical boundary to this which cannot be exceeded? By how much will the floods which have occurred so far, still be exceeded and when will this happen? Can we assess the "most extreme" storm surge which can happen or will there be always a chance that there will be even a higher one coming?

\section{About the XtremRisK Project}

With the aforementioned background, the German "XtremRisK" project (Extreme storm surges at open coasts and estuarine areas: Risk assessment and mitigation under climate change aspects) was launched in 2008 as a joint research project dealing with different aspects of coastal and estuarine flood risks. Different partners from universities and different coastal authorities were involved in this project [see Oumeraci et al., 2015 and the XtremRisK webpage under www.tubraunschweig.de/lwi/hyku/xtremrisk].

The idea was to build on existing knowledge from various European and national projects and to work out some of the open questions in better assessing the flood risk. The project was structured principally following the source-pathway-receptor model [Kundzewicz and Samuels, 1997] with the following subprojects:

- Subproject 1 (SP1): risk sources,

- Subproject 2 (SP2): risk pathways,

- Subproject 3 (SP3): risk receptors,

- Subproject 4 (SP4): integration (risk analysis and assessment).

Data were used from two sites in Germany, one site at the open coast (Sylt island), and another one in an estuary (City of Hamburg). Both sites were data rich since the focus of the project was to improve methods rather than collating more data. Due to the size of the pilot sites and the availability of data, most methods were working on a macro-scale level, where the resolution of flood defences was very often down to a few meters, and consequences were generally estimated considering a house by house level.

The outputs of the project were manifold, ranging from Ph.D. theses to quite some publications in both peer-reviewed journals and conferences (e.g. the FloodRisk 2012 conference in Rotterdam) which reflect the various stages of method 
developments and applications to the pilot sites. An overview of these publications can also be found on the aforementioned webpage.

\section{About this Issue}

The papers in this issue are focussing on various aspects of coastal and estuarine flood risks in Germany. However, since the methods used and further developed within the various subprojects were generic, it is believed that they are adaptable to coastal flood risks in other countries as well. An example of these applications will be discussed in some more detail further below.

The first paper in this issue, Oumeraci et al. [2015], provides an overview of the whole project and its key results and discusses the lessons learnt from the project. The authors underline the process-based methodology of the project and the high level of detail of the studies involved which eventually allow for a simplification of the methods and tools without losing too much information and accuracy.

Various aspects of flood risk sources and extreme events were investigated. Gönnert and Gerkensmeier [2015] use a deterministic approach and data from available water level measurements to better determine the contributions of various constituents of storm surges where the key question was the nonlinearity of the superposition of the analysed constituents. This nonlinearity was confirmed and further detailed by Tayel and Oumeraci [2015] using a hybrid approach based on a hydrodynamic model and an artificial neural network. Wahl et al. [2015] used a statistical approach to propose a storm surge generator, including not only the maximum water level during a storm surge but also its time history. Joint probabilities were estimated for different storm surge scenarios taking into account the water level but also its duration and wave parameters.

Naulin et al. [2015] have looked into various aspects of risk pathways, comprising failure modes for different types of flood defences (dikes, dunes, storm walls, and single point structures), breach models, time-dependency of failure modes considering the time history of storm surges, and length effects of flood defence lines, amongst others. Results have been generated for all pilot sites predicting the initiation conditions for flood inundation models for each of the storm surge scenarios (extreme events) considered.

These input conditions were then used by Ujeyl and Rose [2015] who have run inundation models to estimate the flood extents and flood depths for each storm surge scenario in the pilot sites. From these simulations, they estimated both the direct and indirect economic consequences where especially the latter is an important contribution and shows the large variability of indirect economic consequences as compared to direct ones. In addition, Dassanayake et al. [2015] looked into intangible consequences from floods (loss of life, injuries, cultural losses, environmental losses) and implemented their systematic approaches into the two pilot sites. These results 
were then integrated in a mapping environment using a geographical information system and maps were plotted for the two pilot sites.

Eventually, all these results had to be brought together in a consistent and transparent way especially since the different consequences from floods used different units. Burzel et al. [2015] have developed a GIS-based multi-step procedure to account for these differences and to come up with either a multi-map layer approach or a single score comprising all different units and weights. This Cell-based Risk Assessment (CRA) provides the basis for a consistent mapping procedure of the overall flood risk.

\section{About Its Application}

When results are transferred to other areas there is usually a series of complications which may comprise: (a) different input data (e.g. bathymetry, topography, and land-use); (b) different climate change scenarios; (c) different adaption strategies and defence measures; (d) different socio-economic data; (e) different inundation modelling tools and results; and (f) different scale and resolution requirements. Nevertheless, using a consistent flood risk framework approach, adaptations are possible and will result in a comparable overall risk since the same level of detail is used. Such an example where XtremRisK results were transferred to another area was exemplarily shown in Kortenhaus and Oumeraci [2014].

\section{Acknowledgments}

The XtremRisK project was funded by the German Federal Ministry of Education and Research (BMBF) through the project management of Projektträger Jülich (PTJ) under the Grant Number 03F043B. This support is very gratefully acknowledged here. One of the central keys to success within this project was the availability of datasets for the pilot site areas of Hamburg and Sylt island. Most of the data were provided by the Shipping Administration of the Federal Government (WSA), the Government-Owned Company for Coastal Protection, National Parks and Ocean Protection (LKN), Hamburg Port Authority (HPA) Hamburg and LSBG Hamburg (Agency of Roads, Bridges and Waters, Hamburg). These organisations not only provided the data but also contributed to the analysis and were available in case of questions and any data issues which arose. Without these data the project would not have come that far. Therefore, this support is also gratefully acknowledged here. A joint research project always builds on partners, their networking and their ability to collaborate. Within XtremRisK, the authors feel that this collaboration has worked at its best and often results were only achieved due to the very constructive and effective way of working together and due to the efficient communication in between the XtremRisK partners. This team spirit and the feedback and support from all partners within the project has allowed to produce interesting 
and promising scientific results which would not have been achieved without it. The authors therefore wish to express their greatest acknowledgement to all project partners.

\section{References}

Burzel, A., Dassanayake, D. \& Oumeraci, H. [2015] "Spatial modeling of tangible and intangible losses in integrated coastal flood risk analysis," Coastal Eng. J. 57(1), 1540008.

Dassanayake, D., Burzel, A. \& Oumeraci, H. [2015] "Methods for the evaluation of intangible flood losses and their integration in flood risk analysis," Coastal Eng. J. 57(1), 1540007.

Gönnert, G. \& Gerkensmeier, B. [2015] "A multi-method approach to develop extreme storm surge events to strengthen the resilience of highly vulnerable coastal areas," Coastal Eng. J. 57(1), 1540002 .

Kortenhaus, A. \& Oumeraci, H. [2014] "Flood risk assessments - Results, applications and future requirements," in Proc. 34th Int. Conf. Coastal Engineering (ICCE 2014), ASCE, Seoul, Korea, pp. 10.

Kundzewicz, Z. \& Samuels, P. G. [1997] "Real-time flood forecasting and warning," Conclusions from Workshop and Expert Meeting, Proc. Second RIBAMOD Expert Meeting (DG XII, European Commission, Office for Official Publications of the European Communities, Padova, Italy), p. 277.

Naulin, M., Kortenhaus, A. \& Oumeraci, H. [2015] "Reliability-based flood defense analysis in an integrated risk assessment," Coastal Eng. J. 57(1), 1540005.

Oumeraci, H., Kortenhaus, A., Burzel, A., Naulin, M., Dassanayake, D., Jensen, J., Wahl, T., Mudersbach, C., Gönnert, G., Gerkensmeier, B., Fröhle, P. \& Ujeyl, G. [2015] "XtremRisK Integrated flood risk analysis for extreme storm surges at open coasts and in estuaries: Methodology, key results and lessons learned," Coastal Eng. J. 57(1), 1540001.

Tayel, M. \& Oumeraci, H. [2015] "A hybrid approach using hydrodynamic modeling and artificial neural networks for extreme storm surge prediction," Coastal Eng. J. 57(1), 1540004.

Ujeyl, G. \& Rose, J. [2015] "Estimating direct and indirect damages from storm surges: The case of Hamburg-Wilhelmsburg," Coastal Eng. J. 57(1), 1540006.

Wahl, T., Mudersbach, C. \& Jensen, J. [2015] "Statistical assessment of storm surge scenarios within integrated risk analyses," Coastal Eng. J. 57(1), 1540003. 